\title{
Serum Triiodothyronine, Total Thyroxine, and Thyroxine to Triiodothyronine Ratios in Paired Maternal-Cord Sera and at One Week and One Month of Age
}

\author{
J.M. Montalvo ${ }^{24]}$, H. W. Wahner, W. E. Mayberry, and R. K. Lum \\ Department of Pediatrics, University of Mississippi School of Medicine, Jackson, Mississippi, and \\ Department of Clinical Pathology, Mayo Clinic, Rochester, Minnesota, USA
}

\begin{abstract}
Extract
Twenty-seven paired maternal-cord sera were analyzed for serum triiodothyronine $\left(\mathrm{T}_{3}\right)$, total serum thyroxine ( $\left.\mathrm{TT}_{4}\right)$, and maximum thyroxine globulin binding capacity (TBG cap.). In 17 of the infants the same studies were repeated at 1 week of age and in 10 of the 17 at 1 month. The mean $\mathrm{T}_{3}$ value for the cord sera was $73.1 \pm 20.4$ $\mathrm{ng} / 100 \mathrm{ml}$ while the mean value for the maternal sera was $204 \pm 49$.2. The difference in the mean values was highly significant $(P<0.001)$. The maternal $\mathrm{T}_{3}$ values are comparable with those of nonpregnant control subjects; those of cord blood fall below normal values. No statistically significant difference was found between the $\mathrm{TT}_{4}$ and TBG cap. values for cord and maternal sera. Both values were higher than the normal nonpregnant control values. At 1 week of age the serum $\mathrm{T}_{3}$ levels had increased to a mean of $208.4 \pm 40.9 \mathrm{ng} / 100 \mathrm{ml}$. This mean is significantly different from the one observed in cord sera $(P<0.001)$. A significant increase in the $\mathrm{TT}_{4}$ values, mean $12.53 \pm 2.2 \mu \mathrm{g} / 100 \mathrm{ml}(P<0.01)$, was observed by the end of the 1st week. TBG cap. did not change significantly between birth and 1 week of age; by the end of the lst month of life the serum $\mathrm{TT}_{4}$ had decreased significantly to a mean of $9.5 \pm 2.7$ $\mu \mathrm{g} / 100 \mathrm{ml}(P<0.05)$, while the serum $\mathrm{T}_{3}$ was maintained at a mean level of $228.2 \pm$ $16.9 \mathrm{ng} / 100 \mathrm{ml}$, a value not significantly different from the one observed at 1 week of age.
\end{abstract}

\section{Speculation}

The extremely low levels of $\mathrm{T}_{3}$ in the cord blood in the presence of $\mathrm{TT}_{4}$ and $\mathrm{TBG}$ cap. values equal to those of the maternal blood suggest minimal materno-fetal placental transfer of $T_{3}$. We have postulated that the low fetal $T_{3}$ is responsible for the high levels of pituitary thyrotropic hormone (TSH) present in cord blood and early in the postnatal period and that the high levels of $T T_{4}$ with normal $T_{3}$ levels observed by the end of the 1 st week of life indicate defective peripheral deiodination of thyroxine $\left(\mathrm{T}_{4}\right)$ to $\mathrm{T}_{3}$ and account for the lack of signs and symptoms of hyperthyroidism. By the end of 1 month of age $\mathrm{TT}_{4}$ and $\mathrm{T}_{3}$ values are within normal ranges, which indicates maturation in the metabolic pathway of $\mathrm{T}_{4}$ and $\mathrm{T}_{3}$. 


\section{Introduction}

Thyroxine metabolism in the neonate is still not completely understood. During the first few days of postna. tal life serum hormonal iodine values have been shown to increase significantly $[4,9,10,13,14,16]$. Absence of clinical signs of hyperthyroidism in the presence of laboratory findings suggestive of thyroid hyperactivity continues to be unexplained. Recent evidence that deiodination of $\left(\mathrm{T}_{4}\right)$ to $\left(\mathrm{T}_{3}\right)$ is a prominent pathway of $\mathrm{T}_{4}$ metabolism in normal adults and the development of a sensitive radioimmunoassay for measuring stable $\mathrm{T}_{3}$ in serum [11] prompted the investigation of this pathway of thyroxine metabolism in the newborn period.

\section{Materials and Methods}

Twenty-seven paired maternal and cord sera samples were obtained from normal pregnant women who delivered normal full term infants via the vaginal route without complications. Informed consents were obtained from all subjects in accord with the Helsinki Declaration. Seventeen of the infants were followed for the 1st week of life and 10 of the 17 were followed for the Ist month. All samples were analyzed for $\mathrm{TT}_{4}, \mathrm{~T}_{3}$, and TBG cap. The $\mathrm{TT}_{4}$ was determined by the method of Murphy and Pattee $[1,15]$, serum $T_{3}$ was measured by a radioimmunoassay developed by Gharib et al. [11] who used a highly specific antibody. The TBG cap. was estimated using the reverse flow electrophoresis in tris-maleate buffer at $\mathrm{pH} 8.6[12$, 19]. Thyroxine to triiodothyronine $\left(\mathrm{T}_{4} / \mathrm{T}_{3}\right)$ ratios were calculated from the values obtained for each sample.

\section{Results}

The results in the twenty-seven paired cord and maternal samples are indicated in Table I. Maternal samples had significantly higher $\mathrm{T}_{3}$ levels compared with cord blood $(P<0.001)$. The TBG cap. was found to be significantly higher in the mothers' sera than in cord sera $(P<0.05)$. The $\mathrm{T}_{3}$ values for the maternal sera are comparable with those of nonpregnant control subjects; however, values for cord blood are well below the accepted normal adult values for our laboratory. The thyroxine to triiodothyronine ratios calculated from these values gave a mean $T_{4} / T_{3}$ ratio for the cord blood of $135.2 \pm 39.2$ whereas that for the maternal sera was $55.1 \pm 12$. The difference in the ratio is highly significant $(P<0.001)$. The serum levels of triiodothyronine at 1 week of age increased to a mean of $208.4 \pm 40.9 \mathrm{ng} / 100 \mathrm{ml}$. compared with 73.1 \pm 20.4 for the cord blood. Table II is a longitudinal analysis of the $T_{3}$ values observed for cord blood at 1 week and at 1 month of age, and those for maternal blood. The $\Delta t$ test was applied to the data [5]: $\Delta 1$ denotes the change in $T_{3}$ values from cord blood to 1 week of age, $\Delta 2$ the change from 1 week to 1 month, and $\Delta 3$ the overall change from cord to 1 month in the individual infant. The test data and the $P$ values are recorded at the bottom of the table. As can be seen, a significant increase in $T_{3}$ levels occurred. from birth to 1 week of age but we did not find a significant change in the $\mathrm{T}_{3}$ levels between $\mathrm{I}$ week and 1 month of age. Table III is the longitudinal analysis of the $\mathrm{TT}_{4}$ values in cord blood, at 1 week and at 1 month of age, and those of the maternal blood. The same statistical analysis used in Table II was used for this data. A significant increase in $\mathrm{TT}_{4}$ values was found to occur between $l$ week and $l$ month of age. No significant difference was found in the cord values and those at 1 month of age.

Tables IV and V represent the longitudinal data for TBG cap. and the calculated $T_{4} / T_{3}$ ratios, respectively. As can be seen, there were no significant changes in the TBG cap. between birth and 1 week of age; however, a significant drop took place between 1 week and 1 month. The calculated $\mathrm{T}_{4} / \mathrm{T}_{3}$ ratios showed a significant drop between 1 week and 1 month. Overall we found a significant drop in $T_{4} / T_{3}$ from cord to 1 month.

\section{Discussion}

Our findings of elevated $\mathrm{TT}_{4}$ and $\mathrm{TBG}$ cap. in maternal blood are in accordance with the reports of other investigators who have found these changes to be characteristic of pregnancy $[16,20,22]$. The increase in TBG cap. is secondary to estrogen effects and responsible for the elevation in the $\mathrm{TT}_{4}$. However, the normal serum $T_{3}$ levels observed in the maternal sera indicate that, in contrast to thyroxine, the serum $T_{3}$ concentration is not influenced by elevations in TBG cap. These levels are in accordance with the reports that TBG cap. elevation after estrogen therapy does not increase the serum $T_{3}$ levels [6]. Cord blood had a significantly lower $\mathrm{T}_{3}$ concentration than the paired maternal blood. These lower values were observed in the presence of similar concentrations of serum $\mathrm{T}_{4}$ and $\mathrm{TBG}$ 
Table I. Triiodothyronine $\left(\mathrm{T}_{3}\right)$, total thyroxine $\left(\mathrm{TT}_{4}\right)$, thyroxine binding globulin (TBG) concentration, and thyroxine to triiodothyronine ratios $\left(\mathrm{T}_{4} / \mathrm{T}_{3}\right)$ in maternal and cord sera

\begin{tabular}{|c|c|c|c|c|c|c|c|c|}
\hline \multirow{2}{*}{ Samples } & \multicolumn{2}{|c|}{$\mathrm{T}_{3}, \mathrm{ng} / 100 \mathrm{ml}$} & \multicolumn{2}{|c|}{$\mathrm{TT}_{4}, \mu \mathrm{g} / 100 \mathrm{ml}$} & \multicolumn{2}{|c|}{$\mathrm{TBG}, \mu_{\mathrm{g}}^{\mathrm{g}} / 100 \mathrm{ml}$} & \multicolumn{2}{|c|}{$\mathrm{T}_{4} / \mathrm{T}_{3}$} \\
\hline & Maternal & Cord & Maternal & Cord & Maternal & Cord & Maternal & Cord \\
\hline 1 & 248 & 92.5 & 10.6 & 7.3 & 26.5 & 26.5 & 42.7 & 78.9 \\
\hline 2 & 193 & 103 & $>15.3$ & & & & 77.7 & \\
\hline 3 & 174 & 87 & 10.7 & 11.2 & 30.2 & & 61.5 & 117.89 \\
\hline 4 & 239 & 94 & 6.2 & & 33.0 & & 26.5 & \\
\hline 5 & 229 & 68 & & 6.7 & & 24.9 & & 95.06 \\
\hline 6 & 167 & 90 & 7.0 & 10.6 & 20.0 & 26.5 & 44.0 & 132.5 \\
\hline 7 & 151 & 70 & & & & & & \\
\hline 8 & 245 & 86 & & 6.7 & 41.0 & 25.1 & & 98.12 \\
\hline 9 & 232 & 74 & & 9.0 & & & & \\
\hline 10 & 163 & 63 & 10.5 & 6.5 & 37.5 & & 64.4 & 114.03 \\
\hline 11 & 183 & 52 & 9.6 & & 31.5 & & 52.45 & \\
\hline 12 & 245 & 76 & 10.7 & 11.2 & 38.6 & & 43.63 & 147.36 \\
\hline 13 & 115 & 72 & 7.3 & 11.2 & 21.3 & & 63.47 & 155.55 \\
\hline 14 & 120 & 92 & 6.5 & 12.5 & 20.5 & 32.2 & 54.16 & 135.87 \\
\hline 15 & 273 & 54 & 10.1 & 6.6 & 42.1 & & 35.43 & 122.0 \\
\hline 16 & 298 & 61 & & 11.9 & & & & 195.08 \\
\hline 17 & 288 & 64 & 11.8 & 8.5 & 38.1 & & 42.75 & 114.86 \\
\hline 18 & 268 & 84 & 6.6 & & 28.4 & & 42.03 & \\
\hline 19 & 165 & 85 & 12.4 & 6.9 & 34.9 & 23.9 & 75.15 & 88.46 \\
\hline 20 & 157 & 71 & 11.6 & & 34.2 & & 56.58 & \\
\hline 21 & 180 & 103 & 12.7 & 11.0 & 36.6 & 28.0 & 70.5 & 119.56 \\
\hline 22 & 198 & 83 & 9.9 & & 35.4 & & 50.0 & \\
\hline 23 & 235 & 57 & 13.7 & 10.4 & 35.1 & 27.1 & 68.29 & 182.5 \\
\hline 24 & 183 & 58 & 12.1 & 10.3 & 36.7 & 28.7 & 66.12 & 177.58 \\
\hline 25 & 244 & 53 & 11.9 & 8.8 & 33.9 & 22.2 & 48.7 & 166.0 \\
\hline 26 & 150 & 59 & 10.6 & 13.5 & 35.1 & 25.9 & 70.6 & 228.81 \\
\hline 27 & 196 & 117 & 10.9 & 11.5 & 33.7 & 22.2 & 55.6 & 98.29 \\
\hline Number & 27 & 27 & 22 & 20 & 22 & 12 & 22 & 19 \\
\hline Mean \pm so & $204 \pm 49.2$ & $73.1 \pm 20.4$ & \multicolumn{2}{|c|}{$10.3 \pm 2.49 .6 \pm 2.1$} & \multicolumn{2}{|c|}{$32.9 \pm 6.026 .1 \pm 2.7$} & $55.1 \pm 13.0$ & \\
\hline$t$ Test & \multicolumn{2}{|c|}{13.7} & \multirow{2}{*}{\multicolumn{2}{|c|}{$\begin{array}{l}1.8 \\
<0.1\end{array}$}} & \multirow{2}{*}{\multicolumn{2}{|c|}{$\begin{array}{l}3.7 \\
<0.001\end{array}$}} & \multicolumn{2}{|c|}{$\begin{array}{c}30.1 \pm 10.0103 .2 \pm 39.2 \\
9.8\end{array}$} \\
\hline$P$ & \multicolumn{2}{|c|}{$<0.001$} & & & & & \multicolumn{2}{|c|}{$<0.001$} \\
\hline
\end{tabular}

Table II. A comparison of serum triiodothyronine of $\left(\mathrm{T}_{3}\right)$ levels with statistical analysis ${ }^{1}$

\begin{tabular}{|c|c|c|c|c|c|c|c|}
\hline \multirow{2}{*}{ Sample } & \multicolumn{4}{|c|}{$\mathrm{T}_{3}, \mathrm{ng} / 100 \mathrm{ml}$} & \multirow{2}{*}{$\Delta 1$} & \multirow{2}{*}{$\Delta 2$} & \multirow{2}{*}{$\Delta 3$} \\
\hline & Maternal & Cord & $1 \mathrm{Wk}$ & $1 \mathrm{Mo}$ & & & \\
\hline 1 & 248 & 92.5 & 195 & 167 & -102.5 & 28 & -74.5 \\
\hline 2 & 193 & 103 & 207 & & -104 & & \\
\hline 3 & 174 & 87 & 171 & 112 & -84 & 59 & -25 \\
\hline 4. & 239 & 94 & 260 & & -166 & & \\
\hline 5 & 229 & 68 & 240 & 245 & -172 & -5 & -177 \\
\hline 6 & 167 & 90 & 288 & 188 & -198 & 100 & -98 \\
\hline 8 & 245 & 86 & 214 & & -128 & & \\
\hline 10 & 163 & 63 & & 239 & & & -176 \\
\hline 12 & 245 & 76 & 167 & 249 & -91 & -82 & -173 \\
\hline 13 & 115 & 72 & 154 & & -82 & & \\
\hline 14 & 120 & 92 & 224 & 238 & -132 & -14 & -146 \\
\hline 15 & 273 & 54 & 172 & & -118 & & \\
\hline 16 & 298 & 61 & & 281 & & & -220 \\
\hline 17 & 288 & 64 & 153 & & -89 & & \\
\hline 18 & 268 & 84 & 273 & & -189 & & \\
\hline 23 & 235 & 57 & 224 & & -167 & & \\
\hline 24 & 183 & 58 & 217 & 294 & -159 & -77 & -236 \\
\hline 27 & 196 & 117 & 228 & & -111 & & \\
\hline$n$ & & & & & 16 & 7 & 9 \\
\hline $\bar{\Delta}$ & & & & & -130.78 & 1.28 & -147.27 \\
\hline $\mathrm{sE} \bar{\Delta}$ & & & & & 9.77 & 25.41 & 23.03 \\
\hline$P$ value & & & & & $<0.001$ & NS & $<0.001$ \\
\hline
\end{tabular}

${ }^{1} \Delta_{1}$ denotes the change from cord blood to 1 week of age, $\Delta_{2}$ the change from 1 week to 1 month, and $\Delta_{3}$ the overall change from cord to 1 month in the individual infant. NS : Not significant. 
Table III. A comparison of total thyroxine $\left(\mathrm{TT}_{4}\right)$ levels with statistical analysis ${ }^{1}$

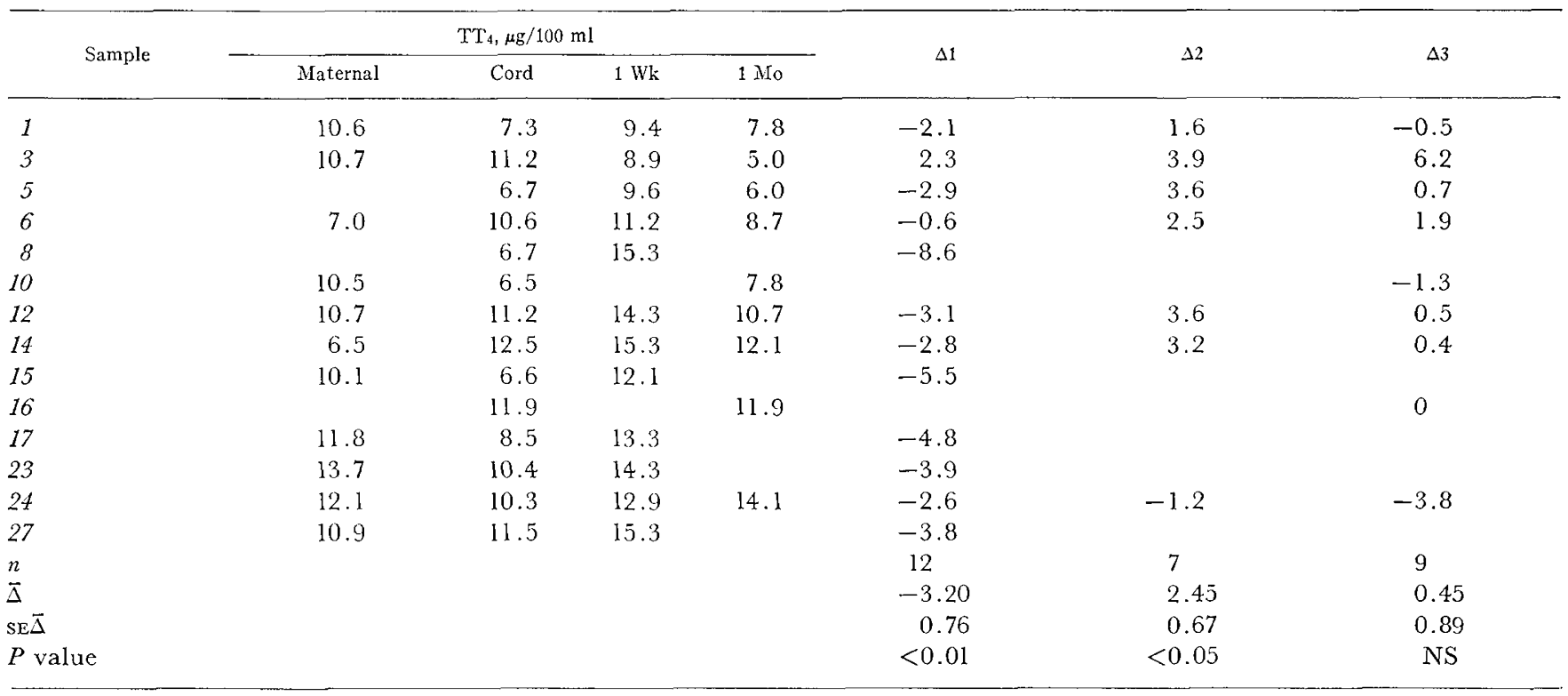

${ }^{1} \Delta_{1}$ denotes the change from cord blood to 1 wcek of age, $\Delta_{2}$ the change from 1 week to one month, and $\Delta_{3}$ the overall change from cord to 1 month in the individual infant. NS : Not significant.

Table IV. A comparison of maximum thyroxine globulin-binding capacity (TBG) with statistical analysis ${ }^{1}$

\begin{tabular}{|c|c|c|c|c|c|c|c|}
\hline \multirow{2}{*}{ Sample } & \multicolumn{4}{|c|}{$\mathrm{TBG}, \mu \mathrm{g} / 100 \mathrm{ml}$} & \multirow{2}{*}{$\Delta 1$} & \multirow{2}{*}{$\Delta 2$} & \multirow{2}{*}{$\Delta 3$} \\
\hline & Maternal & Cord & $1 \mathrm{Wk}$ & $1 \mathrm{Mo}$ & & & \\
\hline 1 & 26.5 & 26.5 & 31.5 & 21.0 & -5.0 & 10.5 & 5.5 \\
\hline 6 & 20.0 & 26.5 & 28.7 & 24.0 & -2.2 & 4.7 & 2.5 \\
\hline 8 & 41.0 & 25.1 & 22.2 & & 2.9 & & \\
\hline 14 & 20.5 & 32.2 & 31.1 & 24.0 & 1.1 & 7.1 & 8.2 \\
\hline 27 & 33.7 & 22.2 & 27.6 & & -5.4 & & \\
\hline$n$ & & & & & 7 & 4 & 5 \\
\hline $\bar{\Delta}$ & & & & & -0.02 & 6.47 & 6.50 \\
\hline$S E \bar{\Delta}$ & & & & & 1.59 & 1.52 & 1.16 \\
\hline$P$ value & & & & & NS & $<0.05$ & $<0.011$ \\
\hline
\end{tabular}

${ }^{1} \Delta_{1}$ denotes the change from cord blood to 1 week of age, $\Delta_{2}$ the change from 1 week to 1 month, and $\Delta_{3}$ the overall change from cord to 1 month in the individual infant. NS: Not significant.

cap. in maternal and cord sera and indicate little or no transplacental transfer of $\mathrm{T}_{3}$. These findings are in accordance with recent animal experimentation which has demonstrated that in thyroidectomized fetal lambs, transfer of $\mathrm{T}_{3}$ across the placenta is minimal [7], but are at a contrast to findings of Dussault et al. [6], who found levels of $T_{3}$ in cord blood to be similar to those of the maternal blood. The difference in the results may be explained by the different methodology used in the two studies. The low levels of $T_{3}$ in the presence of normal $\mathrm{T}_{4}$ levels in cord blood tend to indicate that in the fetus either $T_{3}$ secretion by the fetal gland is decreased or that peripheral conversion of $T_{4} / T_{3}$ is markedly decreased. Pituitary thyrotropic hormone has been shown to be elevated in cord blood and to remain elevated for at least $72 \mathrm{hr}$ after birth $[3,8,21$, 23]. The stimulus for the increased secretion of TSH has not been elucidated. Exposure to cold has been postulated; however, Fisher and Odell [8] demonstrated levels of TSH of the same magnitude as those found in cord blood to be present in blood obtained from scalp veins before delivery. The low circulating 
Table $V$. A comparison of thyroxine to triiodothyronine $\left(\mathrm{T}_{4} / \mathrm{T}_{3}\right)$ ratios with statistical analysis ${ }^{1}$

\begin{tabular}{|c|c|c|c|c|c|c|c|}
\hline \multirow{2}{*}{ Sample } & \multicolumn{4}{|c|}{$\mathrm{T}_{4} / \mathrm{T}_{3}$ ratios } & \multirow{2}{*}{$\Delta 1$} & \multirow{2}{*}{$\Delta 2$} & \multirow{2}{*}{$\Delta 3$} \\
\hline & Maternal & Cord & $1 \mathrm{Wk}$ & $1 \mathrm{Mo}$ & & & \\
\hline 1 & 42.7 & 78.9 & 48.2 & 46.7 & 30.7 & 1.5 & 32.2 \\
\hline 5 & & 95.1 & 40.0 & 24.5 & 55.1 & 15.5 & 70.6 \\
\hline 6 & 44.0 & 132.5 & 38.9 & 46.3 & 93.6 & -7.4 & 86.2 \\
\hline 8 & & 98.1 & 71.5 & & 26.6 & & \\
\hline 14 & 54.2 & 135.9 & 68.3 & 50.8 & 67.6 & 17.5 & 85.1 \\
\hline 15 & 35.4 & 122.0 & 70.3 & & 51.7 & & \\
\hline 16 & & 195.1 & & 42.3 & & & 152.8 \\
\hline 17 & 42.8 & 114.9 & 86.9 & & 28.0 & & \\
\hline 23 & 68.3 & 182.5 & 63.8 & & 118.7 & & \\
\hline 24 & 66.1 & 177.6 & 59.4 & 48.0 & 118.2 & 11.4 & 129.6 \\
\hline$P$ value & & & & & $<0.001$ & NS & $<0.001$ \\
\hline
\end{tabular}

${ }^{1} \Delta_{1}$ denotes the change from cord blood to 1 week of age, $\Delta_{2}$ the change from 1 week to I month, and $\Delta_{3}$ the overall change from cord to 1 month in the individual infant.

levels of $T_{3}$ found in the fetus probably represents the stimulus for TSH hypersecretion in utero and for its persistance in the immediate postnatal period. The present data is in agreement with this hypothesis.

Danowski et al. [4] were first to report the levels of serum protein-bound iodine (PBI) within the newborn period. Their results indicate that within $12 \mathrm{hr}$ after birth the serum PBI in infants was similar to the one present in the maternal blood at the time of delivery with a gradual increase in the levels reaching a peak by the 3rd day and persisting during the entire 1st week of life. The values observed were higher than their accepted standard values for adult euthyroid subjects. Man et al. [13] and Pickering et al. [16], who measured thyroxine-like butanol-extractable iodine (BEI), demonstrated that the levels of BEI are similar in maternal and cord sera, but that a sharp increase occurs during the 1st week of life which reaches a peak by the 5 th day with a return to values similar to those found in cord blood by the 18-20th day of life. Our findings of similar $\mathrm{TT}_{4}$ levels in cord and maternal sera with a rise in the circulating levels of $\mathrm{TT}_{4}$ by 1 week of age and a return to levels equal to those found in the cord blood by 1 month of age are in accordance with the previous data for PBI and BEI in the neonatal period. The marked elevation in $\mathrm{TT}_{4}$ that takes place in the 1st week of life cannot be explained on the basis of changes in TBG cap., inasmuch as TBG cap. values were found not to change significantly during the Ist week of life (Table IV) the decrease in TBG cap. observed to take place between 1 week and 1 month of age could partially, but not completely, explain the $\mathrm{TT}_{4}$ changes observed between 1 week and 1 month of age (Table III). We believe a probable explanation for this change to be forthcoming from our data. To our knowledge, serial determinations of serum $T_{3}$ levels in the cord blood, at 1 week, and at 1 month of age have not been previously reported.

Braverman et al. [21] were first to demonstrate extrathyroidal conversion of $T_{4}$ to $T_{3}$ in man. Pittman et al. [18], in a study of the kinetics of $T_{4}$ to $T_{3}$ conversion in normal adults, demonstrated that the average daily rate of the extrathyroidal conversion of $T_{4}$ to $T_{3}$ was $33 \%$ of the total thyroxine production and that the amount of $\mathrm{T}_{3}$ generated by this pathway contributed $41 \%$ of daily total $\mathrm{T}_{3}$ production. This data proves that extrathyroidal conversion of $T_{4}$ to $T_{3}$ is a major metabolic pathway of $T_{4}$ in normal adults. An equally important, but less efficient, metabolic pathway of $\mathbf{T}_{4}$ in the newborn period can be postulated from our data, which shows that the rapid increase in the circulating levels of $T_{3}$ observed by the end of the lst week of life is associated with abnormally high levels of circulating $T_{4}$ without significant changes in TBG 
cap. A defective peripheral conversion of $T_{4}$ to $T_{3}$ would account for these findings, as well as for the absence of clinical signs of hyperthyroidism in the presence of high circulating levels of $\mathrm{T}_{4}$ and TSH. Without kinetic data we cannot exclude defective thyroidal production of $T_{3}$; however, the ability of the neonatal thyroid to raise the circulating levels of $T_{4}$ to abnormally high levels makes defective peripheral conversion of $T_{4}$ to $T_{3}$ a more attractive hypothesis; the decrease in circulating levels of $T_{4}$ to normal values with maintenance of normal circulating levels of $T_{3}$ observed by 1 month of age tends to indicate a progressive maturation in the metabolic pathways of $T_{4}$ and $T_{3}$. This progressive maturation of enzyme systems is characteristic of the newborn period.

\section{Summary}

Our data shows that in the fetus, the $T_{3}$ levels are extremely low, whereas levels of $\mathrm{TT}_{4}$ and $\mathrm{TBG}$ cap. are comparable with those of the mother. Maternal $\mathrm{T}_{3}$ was not elevated compared with values for nonpregnant subjects, which indicates that TBG cap. elevation does not have a significant effect on circulating $\mathrm{T}_{3}$ levels. The low fetal $T_{3}$ levels suggest little placental transfer. The circulating levels of $T_{3}$ had a significant increase by the end of the lst week of life; this increase was associated with abnormally high levels of circulating $\mathrm{TT}_{4}$ without significant changes in TBG cap. A decrease in $\mathrm{TT}_{4}$ to levels equal to those found in cord blood but with maintenance of normal circulating $\mathrm{T}_{3}$ levels was achieved by 1 month of age.

\section{References and Notes}

1. Asango, G., Mayberry, W. E., and Hockert, T. J., et al.: Total and free human serum thyroxine in normal and abnormal thyroid states. Mayo Clin. Proc. 43: 503 (1968).

2. Braverman, L. E., Ingbar, S. H., and Sterling, K.: Conversion of thyroxine to triiodothyronine in athyreotic human subjects. J. Clin. Invest., 49: 855 (1970).

3. Czernichow, P., Greenberg, A. H., Tyson, J., and Blizzard, R. M.: Thyroid function studied in paired maternal-cord sera and sequential observations of thyrotropic hormone release during the first 72 hours of life. Pediat. Res., 5: 53 (1971).

4. Daiowski, T. S., Johnston, S. Y., Price, W. C., Mickelvy, M., Stevenson, S. S., And McCluskey, E. R.: Protein-bound iodine in infants from birth to one year of age. Pediatrics, 7: 240 (1951).

5. Drxon and Massey: Introduction to Statistical Analysis, Ed. 3, p. 122. (McGraw-Hill, New York, 1969).

6. Dussault, J., Row, V. V., Lickrish, G., and Volpi, R.: Stud- ies of serum triiodothyronine concentration in maternal and cord blood: Transfer of triiodothyronine across the placenta. J. Clin. Endocrinol., 29: 595 (1969).

7. Eremberg, A., Omori, K., Oh, W., Lam, R. W., and Fisher, D. A.: Triiodothyronine kinetics in maternal and thyroidectomized fetal sheep (Abstract). Pediat. Res., 6: 90 (1972).

8. Fisher, D. A., AND Odell, W. D.: Acute relcase of thyrotropin in the newborn. J. Clin. Invest., 48: 1670 (1969).

9. Fiskier, D. A., Odell, W. D., Hobel, C. J., and Garza, R.: Thyroid function in the term fetus. Pediatrics, 44: 526 (1969).

10. Fisher, D. A., ANd Oddie, T. H. L.: Neonatal thyroid hyperactivity. Amer. J. Dis. Child., 107: 574 (1964).

11. Ghardb, H., RYAN, R. J., AND MayberRy, W. E., et al.: Radioimmunoassay for triiodothyronine $\left(\mathrm{T}_{3}\right)$. I. Affinity and specificity of the antibody for $\mathrm{T}_{3}$. J. Clin. Endocrinol. Metabol., 33: 509 (1971).

12. Ingbar, S. H.: Pre-albumin. A thyroxine bixding protein of human plasma. Endocrinology, 63: 256 (1958).

13. Man, E. B., Pickering, D. E., Walker, J., and Cooke, R. E.: Butanol-extractable iodine in the serum of infants. Pediatrics, 9: 32 (1952).

14. Marks, J. F., Hamlin, M., And Zack, P.: Neonatal thyroid function. II. Free thyroxine in infancy. J. Pediat., 68: 559 (1966).

15. Murphy, B. E. P.: The determination of thyroxine by competitive binding protein analysis, cmploying an anion-exchange resin and radiothyroxine. J. Lab. Clin. Med., 66: 161 (1965).

16. Perry, R. E., Hodgman, J. E., And Starr, P.: Maternal cord and serial venous blood protein bound iodine, thyroid-binding globulin, thyroid-binding albumin and pre-albumin in premature infants. Pediatrics, 35: 759 (1965).

17. Pickering, D. E., Kontaxis, N. E., Benson, R. C., and MeeCHAN, R. J.: Thyroid function in the perinatal period. Amer. J. Dis. Child., 95: 616 (1958).

18. Pimman, C. S., Chamberg, J. B., JR., and Read, V. H.: The extrathyroidal conversion rate of thyroxine to triiodothyronine in normal man. J. Clin. Invest., 50: 1187 (1971).

19. Robbins, J.: Reverse-flow zone electrophoresis: A method for detcrmining the thyroxine binding capacity of serum protcin. Arch. Biochem., 63: 461 (1956).

20. Robisins, J., And Nelson, J. H.: Thyroxine binding by serum protein in pregnancy and the newborn. J. Clin. Invest., 37: 153 (1958).

21. Robin, N. I., Refetoff, S., Fang, V., and Selenkow, H. A.: Parameters of thyroid function in maternal and cord serum at term pregnancy. J. Clin. Endocrinol., 29: 1276 (1969).

22. RuSSELl, K. P.: The current status of the protein-bound blood iodine in obstetrics and gynecology. Obstet. Gynecol. Surv., 9: 157 (1954).

23. Utiger, R. D., Wilber, J. F., Cornblath, M., Harm, J. P., and MACK, R. E.: T.S.H. secretion in newborn infants and children (Abstract). J. Clin. Invest., 47:97a.

24. Requests for reprints should be addressed to: J. M. Montalvo, M.D., University of Mississippi School of Medicine, Department of Pediatrics, 2500 N. State Street, Jackson, Miss. 39216 (USA).

25. Accepted for publication March 14, 1973. 